\title{
Autism Spectrum Disorders: Diagnosis and Treatment
}

\author{
Ronan Lordan ${ }^{1,2}$ - Cristiano Storni ${ }^{1,3}$ - Chiara Alessia De Benedictis $1,4,5$ \\ ${ }^{1}$ Autism@UL Special Interest Group, University of Limerick, Limerick, Ireland; ${ }^{2}$ Institute \\ for Translational Medicine and Therapeutics, Perelman School of Medicine, University of \\ Pennsylvania, Philadelphia, PA, USA; ${ }^{3}$ Department of Computer Science and Information \\ System, University of Limerick, Ireland; ${ }^{4}$ Cellular Neurobiology and \\ Neuro-Nanotechnology Lab, Department of Biological Sciences, University of Limerick, \\ Limerick, Ireland; ${ }^{5}$ Bernal Institute, University of Limerick, Limerick, Ireland.
}

Author for correspondence: Chiara Alessia De Benedictis, Department of Biological Sciences, University of Limerick, Limerick, Ireland. E-mail: chiara.debenedictis@ul.ie Doi: https://doi.org/10.36255/exonpublications.autismspectrumdisorders.2021.diagnosis

\begin{abstract}
The diagnostic criteria and treatment approaches of autism spectrum disorders (ASD) have changed greatly over the years. Currently, diagnosis is conducted mainly by observational screening tools that measure a child's social and cognitive abilities. The two main tools used in the diagnosis of ASD are DSM-5 and M-CHAT, which examine persistent deficits in interaction and social communication, and analyze responses to "yes/no" items that cover different developmental domains to formulate a diagnosis. Treatment depends on severity and comorbidities, which can include behavioral training, pharmacological use, and dietary supplement. Behavior-oriented treatments include a series of programs that aim to re-condition target behaviors, and develop vocational, social, cognitive, and living skills. However, to date, no single or combination treatments have been able to reverse ASD completely. This chapter provides an overview of the current diagnostic and treatment strategies of ASD.
\end{abstract}

Keywords: autism spectrum disorders; DSM-5; M-CHAT; treatment; therapy

In: Autism Spectrum Disorders. Grabrucker AM (Editor). Exon Publications, Brisbane, Australia. ISBN: 978-0-6450017-8-5; Doi: https://doi.org/10.36255/exonpublications. autismspectrumdisorders.2021

Copyright: The Authors.

License: This open access article is licenced under Creative Commons Attribution-NonCommercial 4.0 International (CC BY-NC 4.0) https://creativecommons.org/licenses/by-nc/4.0/ 


\section{INTRODUCTION}

Autism spectrum disorders (ASD) are complex, highly heritable neurodevelopmental diseases characterized by individuals with a combination of behavioral and cognitive impairments. These include impaired or diminished social communication skills, repetitive behaviors, and restricted sensory processing or interests (1-3). Swiss psychiatrist Eugen Bleuler first coined the term autism in 1908 to describe symptoms associated with severe schizophrenia, hallucinations, and unconscious fantasy in infants. Since then, the classification, diagnosis, and meaning of autism have radically changed (4). Between the 1940s and 1980s, ASD was described as abnormalities in language development, display of ritualistic and compulsive behaviors, and disturbance in interpersonal relationships. In the 1970s, sensory deficits in infancy were recognized in autistic children and became a defining feature of ASD (4). In 1980, the $3^{\text {rd }}$ edition of the American Psychiatric Association's (APA) Diagnostic and Statistical Manual of Mental Disorders (DSM)-III), listed autism as a subgroup within the diagnostic category of pervasive developmental disorders (PDD) to convey the view that there is a broader spectrum of social communication deficits. The PPD contained four categories: infantile autism, childhood-onset PDD, residual autism, and an atypical form (5). At this point, it was recognized that the previously described symptomatology resembling schizophrenia was not a component of ASD because of the research conducted by Kolvin Rutter and others in the early 1970s. Consequently, childhood schizophrenia was excluded from DSM-III $(1,4)$. In the 1980s, Wing and Gould placed autistic children on a continuum with other abnormal children and discussed autism in behavioral terms rather than psychosis $(4,6)$.

Asperger's syndrome, an ASD named after Hans Asperger, who first described its symptomatology in 1944, gained prominence in the ASD literature due to the works of psychiatrist Lorna Wing, who coined the term in 1976 (4). In 1981, Wing proposed that autism is part of a wider group of conditions that share commonalities, including impairments of communication, imagination, and social interactions. Asperger's syndrome was eventually included in the DSM-IV in 1994 (7). In the mid to late 1980s, works by Simon Baron-Cohen, Uta Frith, and Alan Leslie led to the hypothesis that autistic children lacked "theory of mind", which is the ability to attribute mental states to others and ourselves, an essential component of social interaction (8). In 1990, autism was first classified as a disability (9). Moving to the present day, due to the difficulty in defining and distinguishing between the various PDD, DSM-5 and the International Classification of Diseases $11^{\text {th }}$ revision use 'ASD' as a blanket term and distinguish individuals using clinical specifiers and modifiers (1). Our knowledge of pathology, etiology, and behavior of ASD continues to evolve. Nowadays, ASD is widely recognized as a somewhat common condition that, for many, but not all, requires lifelong support (2).

\section{DIAGNOSIS}

The diagnostic features historically associated with ASD are a triad of impaired social interactions, verbal and nonverbal communication deficits, and restricted, repetitive behavior patterns. These core features are observed irrespective of race, 
ethnicity, culture, or socioeconomic status. However, ASD individuals tend to differ from one another, so one feature may be more prevalent than another $(2,10)$ (see Chapter 1). Despite recent advancements, there are currently no reliable biomarkers for ASD (11). Consequently, today's clinical diagnosis of ASD is based on assessing behaviors as outlined in APA's DSM- 5 criteria $(2,12)$. Other disorders that may co-occur with ASD. These include psychiatric disorders such as attention deficit hyperactivity disorder (ADHD), which is considered the most common comorbidity in people with ASD ( 28\%) (13), along with other conditions and diseases including anxiety and phobias, dissociative disorders, depression, bipolar disorder, and episodic mood disorders $(13,14)$. Physiological disorders (e.g., gastrointestinal disorders) and genetic disorders (e.g., fragile X syndrome) may also be prevalent $(2,14)$.

\section{Hallmarks of ASD and gender prevalence}

In 2010, the prevalence of autism was estimated to be 1 in 132 individuals ( 7.6 per 1,000), affecting approximately 52 million people globally (15). However, estimates can vary due to the diagnostic methodologies used and the definition of ASD adopted in studies. It was approximated in 2016 that 1 in 54 children in the USA was diagnosed with ASD (16). Generally, there appears to be epidemiological evidence of ASD sexual dimorphism. ASD is more prevalent in males than females in a ratio of 3:1, ranging from 2:1 to 5:1 (17). However, it has been proposed that females are more likely to be diagnosed with ASD later than males or may never be diagnosed (18). Biological determinants are now under investigation to resolve whether females have better adaptation/compensatory behaviors or if diagnostic biases play a role $(19,20)$.

Persistent issues with social communication can manifest in various contexts. For example, ASD individuals may persistently fail to hold a normal conversation or have an unorthodox approach to social situations. Some ASD individuals may also present deficits in non-verbal communication behaviors such as difficulty maintaining eye contact or abnormalities in using or understanding body language or gestures. ASD individuals may also have trouble understanding relationships or social interactions that may lead them to have difficulties developing and maintaining relationships (2). Repetitive or restricted behavioral patterns include movements, speech, play, use of objects, resistance to change, and insistence on sameness. In addition, fixations on certain interests with abnormal focus or intensity or periods of hyperactivity and hypoactivity in response to sensory inputs are also associated with ASD. These symptoms are mostly present in early life but may not fully manifest until social interaction is warranted. These symptoms can be somewhat masked later in life by coping strategies learned (2).

\section{Early signs and symptoms}

Early identification and evaluation of ASD in children has become an important public health objective due to the potential association between early intervention and improved development of children with ASD (21-23). Early presentation of ASD often occurs due to parental concerns spurred by recognizing some of the hallmarks of ASD previously outlined (24), which has increased due to greater 
awareness of ASD hallmarks among parents, healthcare specialists, and childcare workers (25). Some video studies suggest that it is possible to identify symptoms of ASD in children as young as 6-12 months old $(26,27)$. There is increased interest to monitor the emergence of ASD prodromes such as reduced motor control or abnormal social development in the first year of life $(24,28)$. As research has developed, it is now known that the prevalence of ASD is particularly high in preterm infants (29), indicating a requirement for additional vigilance in the preterm population.

\section{Diagnostic tools}

Numerous diagnostic guidelines of varying quality are available (30). The essential features of ASD diagnosis include observing a child's relationship and exchange with their parents and with an individual unknown to the child during unstructured and structured assessment activities and a detailed history of the child's development (1). ASD diagnosis can occur at any age but most frequently occurs early in childhood. Although there is a lack of a universal screening instruments, public health systems in various countries in Europe such as Spain and Ireland have programs in place to identify young children with ASD ( 18-30 months) using M-CHAT (Modified Checklist for Autism in Toddlers) and similar tools (31). The sensitivity of these screening methods has been questioned as they fail to identify most children with ASD before their parents have already reported delayed development (32). There may also be racial disparities in early diagnosis of Black and Hispanic children versus white children, which has been reported in the United States. It was found that the first evaluation of ASD in Black children is less likely to occur by 36 months of age than in white children with ASD (40\% early evaluation of black children versus $45 \%$ of white children) (33).

Inconsistencies aside, several standardized screening tools exist to diagnose ASD at an early age, many of which focus on high-risk individuals, e.g., with a family member previously diagnosed with ASD (24). These include the Screening Tool for Autism in Toddlers and Young Children (STAT ${ }^{\mathrm{TM}}$ ), a 20 min observation of young children, established in 2000. The longer and widely researched Autism Diagnostic Observation Schedule (ADOSTM) is a 45 min observation conducted by a professional or clinician to diagnose ASD from 12 months to adulthood (31). There also exists screening tools suitable for research, such as the Diagnostic Instrument for Social Communication Disorders (DISCO) and the Autism Diagnostic Interview-Revised (ADI-R) (31) in the UK. Other screening tools such as the Social Responsiveness Scale (SRS), the Social Communication Questionnaire (SCQ), and the Childhood Autism Rating Scale (CARS) can be used to assess a child's symptoms of ASD. While many tools to screen and diagnose ASD exist, two of the leading autism diagnostic tools in use today are DSM-5 and M-CHAT (Modified Checklist for Autism in Toddlers).

\section{DSM-5}

Since 2013, DSM-5 has been used as a diagnostic tool for ASD worldwide $(1,12)$. According to DSM-5, to be diagnosed with ASD, a child must have persistent 
deficits in the following three areas of social communication and interaction: (i) social-emotional reciprocity; (ii) developing, understanding, and maintaining relationships; and (iii) nonverbal communication. In addition, at least two of the following four behaviors should be present: (i) inflexible to changes in routine; (ii) restrictive or fixated interests that may be abnormal in focus or intensity; (iii) hypo- or hyperactivity in response to sensory input or abnormal fixation with sensory aspects of the environment; and (iv) repetitive movements, speech, or use of items. Symptoms should be present early in the development (in some cases symptoms may be masked in early stages and become prevalent later) and cause clinically significant impairment of function. Finally, ASD may be suspected if the symptoms cannot be better explained by other causes of intellectual disability or developmental issues.

DSM-5 is unique in that it classifies ASD as a spectrum that now also includes Asperger's syndrome. DSM-5 also recognizes that early symptom onset can occur or that the manifestations of ASD may not be recognized until later in childhood or even adulthood, even in those who were monitored early in life (34). Furthermore, under the repetitive and restrictive diagnoses domain, sensationseeking behavior, and hypo-sensory and hyper-sensory responsiveness are now included in DSM-5 in contrast to earlier iterations $(1,35)$. DSM-5 also allows for dual diagnoses of ASD and other comorbidities such as ADHD (28\% of ASD individuals have ADHD) or other co-occurring conditions such as psychiatric disorders (e.g., anxiety, depression, aggression) or genetic disorders (e.g., fragile X syndrome) (31). As a result, DSM-5 is one of the most reliable diagnostic tools of ASD and is trusted internationally. DSM-5 is also used by the Centers for Disease Control and Prevention in the USA (30), UK's National Institute for Health and Care Excellence Guideline (36), and New Zealand's Autism Spectrum Disorder Guidelines (37).

\section{M-CHAT}

M-CHAT, derived from the less sensitive Checklist for Autism in Toddlers (CHAT), and the less common Communication and Symbolic Behavior Scales (CSBS) (38) have become mainstream among parents and even professionals due to their lowcost and accessibility (39). M-CHAT is reliable and has been independently assessed in primary care settings $(40,41)$. M-CHAT is available internationally in several different languages $(42,43)$, and it can now even be accessed electronically via tablet devices (44). The M-CHAT is intended to screen children aged between 16 and 30 months. It contains 23 'yes/no' items that span several developmental domains and encompasses an interview with parents to clarify parent questionnaires and reduce the possibility of false positives (24). This checklist relies on the parent's report of the child's behaviors and skills rather than the observations of a professional. Since 2009, the M-CHAT-revised with follow-up (M-CHAT-R/F) has been validated and is used widely (39). The M-CHAT-R/F) now has 20 'yes/no' items, includes a component for a professional such as a clinician to review, and only necessitates a follow-up interview for those who are perceived to be of medium ASD risk (39). 


\section{TREATMENT}

Whether and to what extent ASD can or should be treated is a controversial topic, especially considering the noticeable heterogeneity within ASD children. Many approaches are available to improve the abilities and skills, and quality of life of individuals with ASD (45-48). These approaches involve families, clinical practitioners, and educators (49). However, to date, information on positive outcomes of a specific intervention, and the mechanism that leads to these improvements is scant (50). In this section, we provide an overview of the current interventional approaches to treat individuals with ASD.

\section{Behavioral therapy}

Depending on the severity and comorbidities, many treatment approaches are available but only a few of these approaches are considered 'evidence-based' with proven benefits (51).

Educational and behavioral interventions play a central role in addressing communication, social skills, play, daily living competencies, academic skills, and inappropriate behavior (52-54). The varied symptoms and functioning levels of autistic individuals requires individualized treatments (55). There is consensus on the importance of providing therapy as soon as possible, immediately after diagnosis or even in the case of suspected diagnosis (56-61). The involvement and training of parents (62-64), siblings, and peers are also important (65).

Applied Behavior Analysis (ABA) is one of the widely used evidence-based approaches (66). ABA interventions operate under the principle of re-conditioning target behavior. The main principle is breaking down specific skills or activities into small elements, and teaching these in a progressive and systematic manner through reinforcement. It has shown substantial improvements in language, IQ, and academic skills $(67,68)$. Discrete Trial Training (DTT), Early Intensive Behavioral Interventions (EIBI), Pivotal Response Training (PRT), and Verbal Behavioral Intervention (VBI) are different types of ABA intervention. DTT is for preschool (3-5 years old) individuals, and it is conducted in a classroom setting (69). It breaks down learning outputs and uses trials of 5 parts to simplifying instructions and teach skills. The parts include cue, prompt, response, consequences, and inter-trial intervals to teach a desired response. EIBI are used for early detection in children who are younger than three years old. VBI involves various protocols that target language and speech (70-72). ABA and DDT are criticized for targeting certain behavior but not the inner motivations underlying such behavior, and its moderate effectiveness in adaptive behavior and socialization (73). Koegel et al. developed a more naturalistic approach to compensate for some of these limitations: the Pivotal Response Treatment (PRT) (73). While ABA is highly structured and led by a therapist, PRT targets key areas (rather than individual behavior) such as motivation, self-management, and initiative in social interaction through playbased and child-initiated activities. The goal is to produce a positive change in the pivotal behaviors that are supposed to lead to improvements in social, communication, and play skills. Often used to complement ABA or DTT approaches in structured settings, PRT is offered in natural environments. 
TEACCH (Treatment and Education of Autistic and related CommunicationHandicapped Children) is commonly used in association with ABA for early intervention $(74,75)$. This framework was developed in the 70 s by Scholper and colleagues. It targets the development of vocational, social, and living skills and teaches these skills in a structured environment where a sequence of activities is organized predictably, often associated with visual prompts (e.g., individualized visual schedules), to support the establishment of learning routines. TEACCH can be used across different environments.

Developmental models focus on teaching skills essential to a child's development, such as emotional relationship and regulation, social communication, and various cognitive abilities. These models usually involve clinical observation of a child's social responses, review of the child's developmental history and evaluation of the child's response to treatments, and in some cases, biomedical evaluation (e.g., genetics). Several developmental models are currently available that show positive outcomes: the Denver Model, the Early Start Denver Model (ESDM), the developmental individual difference (DIR), the Relationship developmental intervention (RDI), and the Responsive Teaching (RT).

The Denver model is one of the most studied developmental models developed initially by Rogers et al. (76). Therapists focus on deficit areas, particularly at the level of imitation, understanding and sharing emotions, theory of mind, and social perception but follow the developmental sequence of normally developed children. Interventions aim at creating a warm environment and positive relationship between children and adults. Teaching mainly occurs in naturalistic settings, involving parents as co-therapists. As the vital role of early intervention is widely acknowledged and the benefits of the Denver Model appreciated, the model has been adapted to toddlers and preschoolers, giving way to the ESDM. Significant improvements in adaptive behavior, language, and IQ were identified in randomized control trials (77).

DIR was developed by Dr. Greenspan in the 1980s and his focus was on 'floor time' and 'child-led' play. DIR also focuses on the child's development. It comprises a series of strategies to enhance relationships and social/emotional communication to support cognitive and emotional development. Instead of identifying deficits, it focuses on meeting the child at his/her developmental levels (e.g., in terms of shared attention and self-regulation, engagement and relating, back and forth interactions and communications, play and symbolic thinking). It also acknowledges the different sensory and motor profiles of the individual by assessing and working on motor planning and sequencing, sensory processing (visual, auditory, proptioceptual), and modulation. Finally, it leverages the children's strengths by establishing relationships and environments that support such strengths to develop emotional, social, and cognitive capabilities. Growing evidence seems to support this approach $(74,78)$.

RDI focuses on activities that facilitate interactive behavior and positive engagement in social relationships to motivate the child to learn social skills and sustain social relationships (74). The program is based on the assumption that autistic children lack flexible thinking, and so it helps them develop dynamic intelligence to cope with changes and new information. RDI has six objectives: emotional referencing, social coordination, declarative language, flexible thinking, relational information processing, foresight and hindsight. Evaluations of this 
approach seem promising, showing reductions in autistic symptoms and increased mainstream placement (79).

Other developmental approaches under the label of "Skill-based developmental training" are also available. These include PECS (Picture Exchange Communication System) and PBS (Positive Behavior Support). PECS is used in children who are non-verbal as it is an augmentative communication system based on exchanging flashcards with images (replacing or integrating speech). It is based on the ABA principles of prompt, reinforce, reward success/correct, and error. Evidence supporting this approach is accumulating (80), but more evidence is needed (81). PBS is a comprehensive intervention that include ABA, normalization/inclusion movements, and person-centered values (82). The main goal is to help the children become more autonomous and less dependent on family members and therapists. One of the distinguishing features of this approach is the idea that changes must occur in the social system and the surrounding environment in which the individual is in, rather than the individual alone (83). This more 'humanistic' approach to treatment tries to focus on manipulating antecedent triggers to maladaptive behavior rather than showing the adverse effects of such behavior. Two PBS techniques have been developed: one is called the antecedentbased techniques (84) and involves the use of visual schedules to build activity patterns and offer choice (84), and the other focuses on understanding the problem behavior and developing educational strategies and reinforcements to improve lifestyle (85).

Several approaches with unproven benefits are also available. These include sensory integration therapy, auditory integration, music therapy, and animalbased therapy. Sensory integration therapy focuses on the neurophysiological processing of sensory information, which is known to be different in autistic individuals. The goal is not to teach a skill or correct behavior but to allow the child to interact with an environment in an adaptive way, thus developing a coping mechanism to correct the underlying sensory-motor dysfunctions (86). The treatment involves engagement of full body movements in environments designed to offer tactile, proprioceptive, gravitational, auditory, visual, and vestibular stimulation. Auditory integration therapy is based on sensory abnormalities and language disorders often associated with auditory issues. Treatment involves exposing children to filtered and modulated music (in terms of volume and pitch). It is based on the assumption that continued exposure to modulated sounds can functionally modify the central auditory processing system, thus impacting language and behavior (87). Animal-based therapy is another intervention that has generated enthusiasm (88). There are several types of animalbased intervention, involving dogs, horses, and dolphins. For example, dolphin-therapy consists of interacting with dolphins in captivity (51). It is believed that these animals can help humans communicate better with one another. Horse-riding therapy is another animal-based intervention based on the idea that it involves multiple functioning domains, including social, cognitive, and gross motor (89). It is also believed that the movements during riding help children self-regulate and demonstrate improvements in distractibility, attention, and social motivation (90). Horse-riding is also called exercise intervention (along with jogging, martial arts, swimming, or yoga/dance), which can result in improvements in numerous behavioral outcomes, including stereotypical behavior, social-emotional functioning, cognition, and attention (91). Music therapy is 
based on the assumption that certain processes in musical improvisation and coordination with other music players may help autistic individuals develop social interaction and communicative skills. Music therapy may help in the emotional and motivational responses of the involved individuals, though conclusive results are still lacking (92).

\section{Pharmacological and dietary interventions}

The most commonly prescribed drugs for individuals with ASD are Abilify (aripiprazole) and Risperdal (risperidone). While the FDA has approved these drugs for use in individuals with ASD, they have not been developed specifically to treat ASD. For example, aripiprazole is an atypical antipsychotic (93). In addition, comorbidities such as gastrointestinal problems (reflux, chronic constipation, and diarrhea) occur in 46-85\% of children with ASD $(94,95)$. Seizures occur in $11-39 \%$ of ASD cases (96). Sleep problems, depression, emotional reactions and behaviors, sinusitis, headaches, mood swings and bipolar disorders are other observed comorbidities (97). Melatonin could effectively treat sleep disturbance and insomnia by improving sleep onset (98-101). Pediatric insomnia is also treated using antihistamines, alpha-2-agonists, benzodiazepines, and chloral hydrate (102). In addition, valproic acid has been used to treat mood swings and bipolar disorders and seizures in people with ASD (103). Another drug for seizures is dimethylglycine (104).

The effects of chelation therapy with 2,3-dimercaptosuccinic acid (DMSA) or 2,3-dimercaptopropane-1-sulfonate (DMPS) to bind and eliminate heavy harmful metals (105), intravenous immunoglobulins to regulate immune response $(106,107)$, and hyperbaric oxygen therapy to decrease the inflammation by increasing the oxygen levels (108) have been equivocal. Gastrointestinal therapy is a diet program that aims to introduce a gluten-free/casein-free diet, considering that peptides derived from gluten and casein may be involved in the origins of autism. No significant beneficial results were reported after this intervention (109). Diet interventions also include introducing vitamins and minerals to restore metal homeostasis, which is crucial for the normal neurodevelopment and brain function. Vitamins B6, C, magnesium, and Omega-3 fatty acids may be linked with improvements in the behavior of children with ASD (110-113).

Several experimental therapies are currently in development. For example, the use of ampakines in the treatment of ASD is presently investigated. Ampakines act as positive modulators of synaptic AMPA-type glutamate receptors. Pre-clinical studies have shown that the ampakines CX1837 and CX1739 can improve learning, memory, and social behaviors in animal models of ASD (114). Insulin-like growth factor 1 (IGF-1) is altered in ASD. Besides many other physiological functions, IGF-1 reduces inflammation by modulating cytokine levels and synapse function. IGF-1 was shown to have beneficial effects in Rett syndrome and ASD $(115,116)$. Similarly, intranasal insulin has shown promising effects in children with Phelan McDermid Syndrome (22q13.3 deletion syndrome), a disorder with frequently occurring autistic behaviors $(117,118)$. Insulin and IGF-1 activate insulin receptors. Intranasal insulin thereby modulates the Ras-MAPK pathway. Trofinetide (NNZ-2566), currently in phase 3 for Rett syndrome and phase 2 for Fragile X syndrome, is a modified form of glypromate, a protein fragment resulting from IGF-1 metabolism in the brain (119). AMO-01 is another RAS-MAPK 
modulator that has been shown to rescue the neuronal phenotype in multiple knockout mouse models of intellectual disability. This drug is currently in Phase 2 clinical trials (120). Thus, targeting IGF-1 signaling seems a promising strategy for the future treatment of ASD.

\section{CONCLUSION}

ASD is a lifelong condition that may result from different genetic and environmental factors. ASD phenotypes vary considerably from one person to another, complicating the diagnosis and treatment strategies. Although significant results have been achieved in the ASD diagnosis, there are no consistent ASD biomarkers at the moment. Over the years, the diagnostic tools have increased. Early identification of children with ASD allows selecting a suitable treatment to improve communication, social and living skills, and reduce maladaptive behaviors and comorbidities. Although significant progress has been made, the therapeutic options to treat individuals with ASD remain limited.

Acknowledgment: This research was supported by funding from NIH (NIH.3247) and NHC (Ref. No. VYB89). Ronan Lordan would like to thank Ms. Eimear Conway for her valuable discussions.

Conflict of interest: The authors declare no potential conflicts of interest with respect to research, authorship, and/or publication of this manuscript.

Copyright and permission statement: The authors confirm that the materials included in this chapter do not violate copyright laws. Where relevant, appropriate permissions have been obtained from the original copyright holder(s), and all original sources have been appropriately acknowledged or referenced.

\section{REFERENCES}

1. Lord C, Charman T, Cusack J, Guillaume D, Frazier T, JH JE, Jones RM, Pickles A, Lounds TJ, Jeremy VV. Autism spectrum disorder (Primer). Nat Rev Dis Primers. 2020;6(1). https://doi.org/10.1038/ s41572-019-0138-4

2. Lord C, Elsabbagh M, Baird G, Veenstra-Vanderweele J. Autism spectrum disorder. Lancet. 2018;392(10146):508-20. https://doi.org/10.1016/S0140-6736(18)31129-2

3. Bauman ML, Kemper TL. Neuroanatomic observations of the brain in autism: a review and future directions. Int J Dev Neurosci. 2005;23(2-3):183-7. https://doi.org/10.1016/j. ijdevneu.2004.09.006

4. Evans B. How autism became autism: The radical transformation of a central concept of child development in Britain. Hist Human Sci. 2013;26(3):3-1. https://doi.org/10.1177/0952695113484320

5. Harris JC. Developmental Neuropsychiatry: Volume II: Assessment, Diagnosis, and Treatment of Developmental Disorders.

6. Wing JK, Hailey AM. Evaluating a community psychiatric service. The Camberwell register 1964-71. 1972.

7. Wing L. Asperger's syndrome: a clinical account. Psychol Med. 1981;11(1):115-29. https://doi. org/10.1017/S0033291700053332 
8. Baron-Cohen SI, Leslie AM, Frith U. Do children with autism have a "theory of mind"? Cognition. 1985;21:37-46. https://doi.org/10.1016/0010-0277(85)90022-8

9. King BH, Navot N, Bernier R, Webb SJ. Update on diagnostic classification in autism. Curr Opin Psychiatry. 2014;27(2):105. https://doi.org/10.1097/YCO.0000000000000040

10. Khan NZ, Gallo LA, Arghir A, Budisteanu B, Budisteanu M, Dobrescu I, Donald K, El-Tabari S, Hoogenhout M, Kalambayi F, Kawa R. Autism and the grand challenges in global mental health. Autism Res. 2012;5(3):156-159. https://doi.org/10.1002/aur.1239

11. Shen L, Liu X, Zhang H, Lin J, Feng C, Iqbal J. Biomarkers in autism spectrum disorders: current progress. Clin Chim Acta. 2020;502:41-54. https://doi.org/10.1016/j.cca.2019.12.009

12. American Psychiatric Association. Diagnostic and statistical manual of mental disorders (DSM-5®). American Psychiatric Pub. 2013. https://doi.org/10.1176/appi.books.9780890425596

13. Simonoff S, Pickles A, Charman T, Chandler S, Loucas, T, Baird G. Psychiatric disorders in children with autism spectrum disorders: prevalence, comborbidity, and associated factors in a population-derived sample. Journal of the American Academy of Child \& Adolescent Psychiatry. 2008;47(8):921-9. https://doi.org/10.1097/CHI.0b013e318179964f

14. Doshi-Velez F, Ge Y, Kohane I. Comorbidity clusters in autism spectrum disorders: an electronic health record time-series analysis. Pediatrics. 2014;133(1):e54-63. https://doi.org/10.1542/ peds.2013-0819

15. Baxter AJ, Brugha TS, Erskine HE, Scheurer RW, Vos T, Scott JG. The epidemiology and global burden of autism spectrum disorders. Psychol Med. 2015;45(3):601. https://doi.org/10.1017/ S003329171400172X

16. Shaw KA, Maenner MJ, Baio J. Early identification of autism spectrum disorder among children aged 4 years-Early Autism and Developmental Disabilities Monitoring Network, six sites, United States, 2016. MMWR Surveillance Summaries. 2020;69(3):1. https://doi.org/10.15585/mmwr.ss6903al

17. Loomes R, Hull L, Mandy WP. What is the male-to-female ratio in autism spectrum disorder? A systematic review and meta-analysis. J Am Acad Child Adolesc Psychiatry. 2017;56(6):466-74. https:// doi.org/10.1016/j.jaac.2017.03.013

18. Werling DM, Geschwind DH. Understanding sex bias in autism spectrum disorder. Proc Natl Acad Sci U S A. 2013;110(13):4868-9. https://doi.org/10.1073/pnas.1301602110

19. Navarro-Pardo E, López-Ramón F, Alonso-Esteban Y, Alcantud-Marín F. Diagnostic Tools for Autism Spectrum Disorders by Gender: Analysis of Current Status and Future Lines. Children. 2021;8(4):262. https://doi.org/10.3390/children8040262

20. Dworzynski K, Ronald A, Bolton P, Happé F. How different are girls and boys above and below the diagnostic threshold for autism spectrum disorders?. J Am Acad Child Adolesc Psychiatry. 2012;51(8):788-97. https://doi.org/10.1016/j.jaac.2012.05.018

21. Johnson CP, Myers SM. Identification and evaluation of children with autism spectrum disorders. Pediatrics. 2007;120(5):1183-215. https://doi.org/10.1542/peds.2007-2361

22. Reichow B, Barton EE, Boyd BA, Hume K. Early intensive behavioral intervention (EIBI) for young children with autism spectrum disorders (ASD). Cochrane Database Syst Rev. 2012(10). https://doi. org/10.1002/14651858.CD009260.pub2

23. Rogers SJ, Estes A, Lord C, Munson J, Rocha M, Winter J, Greenson J, Colombi C, Dawson G, Vismara LA, Sugar CA. A multisite randomized controlled two-phase trial of the Early Start Denver Model compared to treatment as usual. J Am Acad Child Adolesc Psychiatry. 2019;58(9):853-65. https://doi.org/10.1016/j.jaac.2019.01.004

24. Zwaigenbaum L, Penner M. Autism spectrum disorder: advances in diagnosis and evaluation. Bmj. 2018;361. https://doi.org/10.1136/bmj.k1674

25. Dover CJ, Le Couteur A. How to diagnose autism. Archives of disease in childhood. 2007; 92(6):540-5. https://doi.org/10.1136/adc.2005.086280

26. Baranek GT. Autism during infancy: A retrospective video analysis of sensory-motor and social behaviors at 9-12 months of age. J Autism Dev Disord. 1999;29(3):213-24. https://doi. org/10.1023/A: 1023080005650

27. Maestro S, Muratori F, Cavallaro MC, Pei F, Stern D, Golse B, Palacio-Espasa F. Attentional skills during the first 6 months of age in autism spectrum disorder. J Am Acad Child Adolesc Psychiatry. 2002;41(10):1239-45. https://doi.org/10.1097/00004583-200210000-00014 
28. Yirmiya N, Charman T. The prodrome of autism: early behavioral and biological signs, regression, peri-and post-natal development and genetics. J Child Psychol Psychiatry. 2010;51(4):432-58. https://doi.org/10.1111/j.1469-7610.2010.02214.x

29. Agrawal N, Arevalo S, Castillo C, Lucas AT. Effectiveness of the Asking Saves Kids gun violence prevention campaign in an urban pediatric clinic.

30. Penner M, Anagnostou E, Andoni LY, Ungar WJ. Systematic review of clinical guidance documents for autism spectrum disorder diagnostic assessment in select regions. Autism. 2018;22(5):517-27. https://doi.org/10.1177/1362361316685879

31. Blank MS, Turner JB, Fisher PW, Guthrie EB, Whitaker AH. The Need for a Clinically Useful Schema of Social Communication. J Am Acad Child Adolesc Psychiatry. 2020;59(11):1198-200. https://doi. org/10.1016/j.jaac.2020.03.011

32. Mandell D, Mandy W. Should all young children be screened for autism spectrum disorder?

33. Shaw KA, Maenner MJ, Baio J. Early identification of autism spectrum disorder among children aged 4 years-Early Autism and Developmental Disabilities Monitoring Network, six sites, United States, 2016. MMWR Surveill Summ. 2020;69(3):1. https://doi.org/10.15585/mmwr.ss6903al

34. Ozonoff S, Young GS, Brian J, Charman T, Shephard E, Solish A, Zwaigenbaum L. Diagnosis of autism spectrum disorder after age 5 in children evaluated longitudinally since infancy. J Am Acad Child Adolesc Psychiatry. 2018;57(11):849-57. https://doi.org/10.1016/j.jaac.2018.06.022

35. Green D, Chandler S, Charman T, Simonoff E, Baird G. Brief report: DSM-5 sensory behaviours in children with and without an autism spectrum disorder. J Autism Dev Disord 2016;46(11):3597-606. https://doi.org/10.1007/s10803-016-2881-7

36. Yates K, Le Couteur A. Diagnosing autism/autism spectrum disorders. J Paediatr Child Health. 2016;26(12):513-8. https://doi.org/10.1016/j.paed.2016.08.004

37. Hasselbusch A. "Contribution" in: Ministries of Health and Education. New Zealand Autism Spectrum Disorder Guideline.

38. McConachie H, Parr JR, Glod M, Hanratty J, Livingstone N, Oono IP, Robalino S, Baird G, Beresford B, Charman T, Garland D. Systematic review of tools to measure outcomes for young children with autism spectrum disorder.

39. Robins DL, Fein D, Barton M. The modified checklist for autism in toddlers, revised with follow-up (M-CHAT-R/F). Pediatrics. 2009;133:37-45. https://doi.org/10.1542/peds.2013-1813

40. Pandey J, Verbalis A, Robins DL, Boorstein H, Klin AM, Babitz T, Chawarska K, Volkmar F, Green J, Barton M, Fein D. Screening for autism in older and younger toddlers with the Modified Checklist for Autism in Toddlers. Autism. 2008;12(5):513-35. https://doi.org/10.1177/1362361308094503

41. Robins DL. Screening for autism spectrum disorders in primary care settings. Autism. 2008;12(5):537-56. https://doi.org/10.1177/1362361308094502

42. Canal-Bedia R, García-Primo P, Martín-Cilleros MV, Santos-Borbujo J, Guisuraga-Fernández Z, Herráez-García L, del Mar Herráez-García M, Boada-Muñoz L, Fuentes-Biggi J, Posada-de La Paz M. Modified checklist for autism in toddlers: cross-cultural adaptation and validation in Spain. J Autism Dev Disord. 2011;41(10):1342-51. https://doi.org/10.1007/s10803-010-1163-z

43. Baduel S, Guillon Q, Afzali MH, Foudon N, Kruck J, Rogé B. The French version of the Modified-Checklist for Autism in Toddlers (M-CHAT): a validation study on a French sample of 24 month-old children. J Autism Dev Disord. 2017;47(2):297-304. https://doi.org/10.1007/ sl0803-016-2950-y

44. Campbell K, Carpenter KL, Espinosa S, Hashemi J, Qiu Q, Tepper M, Calderbank R, Sapiro G, Egger HL, Baker JP, Dawson G. Use of a digital modified checklist for autism in toddlers-revised with follow-up to improve quality of screening for autism. J Pediatr. 2017;183:133-9. https://doi. org/10.1016/j.jpeds.2017.01.021

45. den Houting, Jacquiline. "Neurodiversity: An insider's perspective." (2019): 271-273. https://doi. org/10.1177/1362361318820762

46. Sandbank M, Bottema-Beutel K, Crowley S, Cassidy M, Dunham K, Feldman JI, Crank J, Albarran SA, Raj S, Mahbub P, Woynaroski TG. Project AIM: Autism intervention meta-analysis for studies of young children. Psychol Bull. 2020;146(1):1. https://doi.org/10.1037/bul0000215

47. Myers SM, Johnson CP. Management of children with autism spectrum disorders. Pediatrics. 2007;120(5):1162-82. https://doi.org/10.1542/peds.2007-2362 
48. Oswald TM, Winder-Patel B, Ruder S, Xing G, Stahmer A, Solomon M. A pilot randomized controlled trial of the ACCESS program: a group intervention to improve social, adaptive functioning, stress coping, and self-determination outcomes in young adults with autism spectrum disorder. J Autism Dev Disord. 2018;48(5):1742-60. https://doi.org/10.1007/s10803-017-3421-9

49. Lord C, Brugha TS, Charman T, Cusack J, Dumas G, Frazier T, Jones EJ, Jones RM, Pickles A, State MW, Taylor JL. Autism spectrum disorder. Nat Rev Dis. 2020;6(1):1-23. https://doi.org/10.1038/ s41572-019-0138-4

50. Weitlauf AS, McPheeters ML, Peters B, Sathe N, Travis R, Aiello R, Williamson E, Veenstra-VanderWeele J, Krishnaswami S, Jerome R, Warren Z. Therapies for children with autism spectrum disorder. 2014.

51. Medavarapu S, Marella LL, Sangem A, Kairam R. Where is the evidence? A narrative literature review of the treatment modalities for autism spectrum disorders. Cureus. 2019;11(1). https://doi. org/10.7759/cureus.3901

52. Maglione MA, Gans D, Das L, Timbie J, Kasari C. Nonmedical interventions for children with ASD: Recommended guidelines and further research needs. Pediatrics. 2012;130(Supplement 2):S169-78. https://doi.org/10.1542/peds.2012-09000

53. Whitehouse AJ, Granich J, Alvares G, Busacca M, Cooper MN, Dass A, Duong T, Harper R, Marshall W, Richdale A, Rodwell T. A randomised controlled trial of an iP ad-based application to complement early behavioural intervention in Autism Spectrum Disorder. J Child Psychol Psychiatry. 2017;58(9):1042-52. https://doi.org/10.1111/jcpp.12752

54. Myers SM, Johnson CP, American Academy of Pediatrics Council on Children With Disabilities. Management of children with autism spectrum disorders. Pediatrics. 2007;120:1162-1182. https:// doi.org/10.1542/peds.2007-2362

55. Zwaigenbaum L, Bryson S, Lord C, et al. Clinical assessment and management of toddlers with suspected autism spectrum disorder: insights from studies of high-risk infants. Pediatrics. 2009;123(5):1383-1391. https://doi.org/10.1542/peds.2008-1606

56. Zwaigenbaum L, Bauman ML, Choueiri R, Kasari C, Carter A, Granpeesheh D, Mailloux Z, Roley SS, Wagner S, Fein D, Pierce K. Early intervention for children with autism spectrum disorder under 3 years of age: recommendations for practice and research. Pediatrics. 2015;136(Supplement 1): S60-81. https://doi.org/10.1542/peds.2014-3667E

57. Tachibana Y, Miyazaki C, Ota E, Mori R, Hwang Y, Kobayashi E, Terasaka A, Tang J, Kamio Y. A systematic review and meta-analysis of comprehensive interventions for pre-school children with autism spectrum disorder (ASD). PloS one. 2017;12(12):e0186502. https://doi.org/10.1371/journal. pone.0186502

58. Kossyvaki L, Papoudi D. A review of play interventions for children with autism at school. Intl J Disabil Dev Educ. 2016;63(1):45-63. https://doi.org/10.1080/1034912X.2015.1111303

59. Chang YC, Locke J. A systematic review of peer-mediated interventions for children with autism spectrum disorder. Res Autism Spectr Disord. 2016;27:1-0. https://doi.org/10.1016/j.rasd.2016.03.010

60. Watkins L, O'Reilly M, Kuhn M, Gevarter C, Lancioni GE, Sigafoos J, Lang R. A review of peermediated social interaction interventions for students with autism in inclusive settings. J Autism Dev Disord. 2015;45(4):1070-83. https://doi.org/10.1007/s10803-014-2264-x

61. Zagona AL, Mastergeorge AM. An empirical review of peer-mediated interventions: Implications for young children with autism spectrum disorders. Focus Autism Other Dev Disabl. 2018;33(3): 131-41. https://doi.org/10.1177/1088357616671295

62. Siller M, Morgan L. Systematic review of research evaluating parent-mediated interventions for young children with autism: Years 2013 to 2015. Handbook of parent-implemented interventions for very young children with autism. 2018:1-21. https://doi.org/10.1007/978-3-319-90994-3_1

63. Shivers CM, Plavnick JB. Sibling involvement in interventions for individuals with autism spectrum disorders: A systematic review. J Autism Dev Disord. 2015;45(3):685-96. https://doi.org/10.1007/ s10803-014-2222-7

64. Prata J, Lawson W, Coelho R. Parent training for parents of children on the autism spectrum: A review. Int J Clin Neurosci Ment Health. 2018;5:3. https://doi.org/10.21035/ijcnmh.2018.5.3

65. Park HA, Kim JI, Kim Y, Park S, Yang Y, Lee Y, Lee H, Kim SY, Kim BN. Autism spectrum disorder and behavioral intervention: An Updated Review. J Korean Acad Child Adolesc Psychiatry. 2015;26(2):86-93. https://doi.org/10.5765/jkacap.2015.26.2.86 
66. Makrygianni MK, Gena A, Katoudi S, Galanis P. The effectiveness of applied behavior analytic interventions for children with Autism Spectrum Disorder: A meta-analytic study. Res Autism Spectr Disord. 2018;51:18-31. https://doi.org/10.1016/j.rasd.2018.03.006

67. Lovaas OI. Behavioral treatment and normal educational and intellectual functioning in young autistic children. J Consult Clin Psychol. 1987;55(1):3. https://doi.org/10.1037/0022-006X.55.1.3

68. Virués-Ortega J. Applied behavior analytic intervention for autism in early childhood: Metaanalysis, meta-regression and dose-response meta-analysis of multiple outcomes. Clin Psychol Rev. 2010;30(4):387-99. https://doi.org/10.1016/j.cpr.2010.01.008

69. Smith T. Discrete trial training in the treatment of autism. Focus Autism Other Dev Disabl. 2001;16(2):86-92. https://doi.org/10.1177/108835760101600204

70. Reichow B, Wolery M. Comprehensive synthesis of early intensive behavioral interventions for young children with autism based on the UCLA young autism project model. J Autism Dev Disord. 2009;39(1):23. https://doi.org/10.1007/s10803-008-0596-0

71. Reichow B, Barton EE, Boyd BA, Hume K. Early intensive behavioral intervention (EIBI) for young children with autism spectrum disorders (ASD). Cochrane Database Syst Rev. 2012(10). https://doi. org/10.1002/14651858.CD009260.pub2

72. Ackley M, Subramanian JW, Moore JW, Litten S, Lundy MP, Bishop SK. A review of language development protocols for individuals with autism. J Behav Educ. 2019;28(3):362-88. https://doi. org/10.1007/s10864-019-09327-8

73. Koegel LK, Koegel RL, Harrower JK, Carter CM. Pivotal response intervention I: Overview of approach. J Assoc Pers Sev Handicaps. 1999;24(3):174-85. https://doi.org/10.2511/rpsd.24.3.174

74. Myers SM, Johnson CP. Management of children with autism spectrum disorders. Pediatrics. 2007;120(5):1162-82. https://doi.org/10.1542/peds.2007-2362

75. Gresham FM, Beebe-Frankenberger ME, MacMillan DL. A selective review of treatments for children with autism: Description and methodological considerations. School Psych Rev. 1999;28(4):559-75. https://doi.org/10.1080/02796015.1999.12085985

76. Vismara LA, Rogers SJ. The early start denver model:a case study of an innovative practice. J Early Interv. 2008;31:91-108. https://doi.org/10.1177/1053815108325578

77. Dawson G, Rogers S, Munson J, Smith M, Winter J, Greenson J, et al. Randomized, controlled trial of an intervention for toddlers with autism:the Early Start Denver Model. Pediatrics. 2010;125:e17-e23. https://doi.org/10.1542/peds.2009-0958

78. Casenhiser DM, Shanker SG, Stieben J. Learning through interaction in children with autism:preliminary data from asocial-communication-based intervention. Autism. 2013;17:220-241. https://doi.org/10.1177/1362361311422052

79. Gutstein SE, Burgess AF, Montfort K. Evaluation of the relationship development intervention program. Autism. 2007;11(5):397-411. https://doi.org/10.1177/1362361307079603

80. Howlin P, Gordon RK, Pasco G, Wade A, Charman T. The effectiveness of Picture Exchange Communication System (PECS) training for teachers of children with autism: a pragmatic, group randomised controlled trial. J Child Psychol Psychiatry. 2007;48(5):473-81. https://doi. org/10.1111/j.1469-7610.2006.01707.x

81. Carr D, Felce J. The effects of PECS teaching to Phase III on the communicative interactions between children with autism and their teachers. J Autism Dev Disord. 2007;37(4):724-37. https://doi. org/10.1007/s10803-006-0203-1

82. Sugai G, Horner RH, Dunlap G, Hieneman M, Lewis TJ, Nelson CM, et al. Applying Positive Behavior Support and Functional Behavioral Assessment in Schools. J Posit Behav Intervs. 2000;2:131-143. https://doi.org/10.1177/109830070000200302

83. Carr EG, Dunlap G, Horner RH, Koegel RL, Turnbull AP, Sailor W. Positive behavior support:evolution of an applied science. J Posit Behav Interv. 2002;4:4-16. https://doi.org/10.1177/109830070200400102

84. Repp AC, Horner RH. Functional analysis of problem behavior:from effective assessment to effective support. Belmont: Wadsworth Publishing Company; 1999.

85. Horner RH, Carr EG. Behavioral support for students with severe disabilities:functional assessment and comprehensive intervention. J Spec Educ. 1997;31:84-104. https://doi. org/10.1177/002246699703100108 
86. Case-Smith J, Bryan T. The effects of occupational therapy with sensory integration emphasis on preschool-age children with autism. Am J Occup Ther. 1999;53(5):489-97. https://doi.org/10.5014/ ajot.53.5.489

87. Rimland B, Edelson SM. Brief report: A pilot study of auditory integration training in autism. Journal of autism and developmental disorders. 1995 Feb 1;25(1):61-70. https://doi.org/10.1007/BF02178168

88. Davis TN, Scalzo R, Butler E, Stauffer M, Farah YN, Perez S, Mainor K, Clark C, Miller S, Kobylecky A, Coviello L. Animal assisted interventions for children with autism spectrum disorder: A systematic review. Educ Train Autism Dev Disabili. 2015;1:316-29.

89. Bass MM, Duchowny CA, Llabre MM. The effect of therapeutic horseback riding on social functioning in children with autism. J Autism Dev Disord. 2009;39(9):1261-7. https://doi.org/10.1007/ s10803-009-0734-3

90. Srinivasan SM, Cavagnino DT, Bhat AN. Effects of equine therapy on individuals with autism spectrum disorder: A systematic review. Journal Autism Dev Disord. 2018;5(2):156-75. https://doi. org/10.1007/s40489-018-0130-z

91. Bremer E, Crozier M, Lloyd M. A systematic review of the behavioural outcomes following exercise interventions for children and youth with autism spectrum disorder. Autism. 2016;20(8):899-915. https://doi.org/10.1177/1362361315616002

92. Kim J, Wigram T, Gold C. Emotional, motivational and interpersonal responsiveness of children with autism in improvisational music therapy. Autism. 2009;13(4):389-409. https://doi. org/10.1177/1362361309105660

93. Owen R, Sikich L, Marcus RN, Corey-Lisle P, Manos G, McQuade RD, Carson WH, Findling RL. Aripiprazole in the treatment of irritability in children and adolescents with autistic disorder. Pediatrics. 2009;124(6):1533-40. https://doi.org/10.1542/peds.2008-3782

94. Horvath K, Perman JA. Autism and gastrointestinal symptoms. Curr Gastroenterol Rep. 2002;4(3): 251-8. https://doi.org/10.1007/s11894-002-0071-6

95. Schneider CK, Melmed RD, Barstow LE, Enriquez FJ, Ranger-Moore J, Ostrem JA. Oral human immunoglobulin for children with autism and gastrointestinal dysfunction: a prospective, open-label study. J Autism Dev Disord. 2006;36(8):1053-64. https://doi.org/10.1007/s10803-006-0141-y

96. Ballaban-Gil K, Tuchman R. Epilepsy and epileptiform EEG: association with autism and language disorders. Ment Retard Dev Disabil Res Rev. 2000;6(4):300-8. https://doi. org/10.1002/1098-2779(2000)6:4<300::AID-MRDD9>3.0.CO;2-R

97. Sanchack K, Thomas CA. Autism spectrum disorder: Primary care principles. Am Fam Physician. 2016;94(12):972-9.

98. Tordjman S, Najjar I, Bellissant E, Anderson GM, Barburoth M, Cohen D, Jaafari N, Schischmanoff O, Fagard R, Lagdas E, Kermarrec S. Advances in the research of melatonin in autism spectrum disorders: literature review and new perspectives. Int J Mol Sci. 2013;14(10):20508-42. https://doi. org/10.3390/ijms141020508

99. Paavonen EJ, Nieminen-von Wendt T, Vanhala R, Aronen ET, von Wendt L. Effectiveness of melatonin in the treatment of sleep disturbances in children with Asperger disorder. J Child Adolesc Psychopharmacol. 2003;13(1):83-95. https://doi.org/10.1089/104454603321666225

100. Phillips L, Appleton RE. Systematic review of melatonin treatment in children with neurodevelopmental disabilities and sleep impairment. Dev Med Child Neurol. 2004;46(11):771-5. https://doi. org/10.1111/j.1469-8749.2004.tb00998.x

101. Giannotti F, Cortesi F, Cerquiglini A, Bernabei P. An open-label study of controlled-release melatonin in treatment of sleep disorders in children with autism. J Autism Dev Disord. 2006;36(6):741-52. https://doi.org/10.1007/s10803-006-0116-z

102. Owens JA, Babcock D, Blumer J, Chervin R, Ferber R, Goetting M, Glaze D, Ivanenko A, Mindell J, Rappley M, Rosen C. The use of pharmacotherapy in the treatment of pediatric insomnia in primary care: rational approaches. A consensus meeting summary. J Clin Sleep Med. 2005;1(01):49-59. https://doi.org/10.5664/jcsm.26297

103. Pasquali R, Stener-Victorin E, Yildiz BO, Duleba AJ, Hoeger K, Mason H, Homburg R, Hickey T, Franks S, Tapanainen JS, Balen A. PCOS Forum: research in polycystic ovary syndrome today and tomorrow. Clin Endocrinol. 2011;74(4):424-33. https://doi.org/10.1111/j.1365-2265.2010.03956.x 
104. Kern JK, Miller VS, Cauller L, Kendall R, Mehta J, Dodd M. Effectiveness of N, N-dimethylglycine in autism and pervasive developmental disorder. J Child Neurol. 2001;16(3):169-73. https://doi. org/10.1177/088307380101600303

105. Nelson KB, Bauman ML. Thimerosal and autism?. Pediatrics. 2003;111(3):674-9. https://doi. org/10.1542/peds.111.3.674

106. Plioplys AV. Intravenous immunoglobulin treatment of children with autism. J Child Neurol. 1998;13(2):79-82. https://doi.org/10.1177/088307389801300207

107. DelGiudice-Asch G, Simon L, Schmeidler J, Cunningham-Rundles C, Hollander E. Brief report: a pilot open clinical trial of intravenous immunoglobulin in childhood autism. J Autism Dev Disord. 1999;29(2):157-60. https://doi.org/10.1023/A:1023096728131

108. Granpeesheh D, Tarbox J, Dixon DR, Wilke AE, Allen MS, Bradstreet JJ. Randomized trial of hyperbaric oxygen therapy for children with autism. Res Autism Spectr Disord. 2010;4(2):268-75. https:// doi.org/10.1016/j.rasd.2009.09.014

109. Elder JH, Shankar M, Shuster J, Theriaque D, Burns S, Sherrill L. The gluten-free, casein-free diet in autism: results of a preliminary double blind clinical trial. J Autism Dev Disord. 2006;36(3):413-20. https://doi.org/10.1007/s10803-006-0079-0

110. Kuriyama S, Kamiyama M, Watanabe M, Tamahashi S, Muraguchi I, Watanabe T, Hozawa A, Ohkubo T, Nishino Y, Tsubono Y, Tsuji I. Pyridoxine treatment in a subgroup of children with pervasive developmental disorders. Dev Med Child Neurol. 2002;44(4):283-6. https://doi.org/10.1017/ S0012162201232071

111. Adams JB, Holloway C. Pilot study of a moderate dose multivitamin/mineral supplement for children with autistic spectrum disorder. J Altern Complement Med. 2004;10(6):1033-9. https://doi. org/10.1089/acm.2004.10.1033

112. Bell JG, MacKinlay EE, DickJR, MacDonald DJ, Boyle RM, Glen AC. Essential fatty acids and phospholipase A2 in autistic spectrum disorders. Prostaglandins Leukot Essent. Fatty Acids. 2004;71(4):201-4. https://doi.org/10.1016/j.plefa.2004.03.008

113. Politi P, Cena H, Comelli M, Marrone G, Allegri C, Emanuele E, di Nemi SU. Behavioral effects of omega-3 fatty acid supplementation in young adults with severe autism: an open label study. Arch Medical Res. 2008;39(7):682-5. https://doi.org/10.1016/j.arcmed.2008.06.005

114. Delorme R, Ey E, Toro R, Leboyer M, Gillberg C, Bourgeron T. Progress toward treatments for synaptic defects in autism. Nat Med. 2013;19(6):685-94. https://doi.org/10.1038/nm.3193

115. Khwaja OS, Ho E, Barnes KV, O'Leary HM, Pereira LM, Finkelstein Y, Nelson CA, Vogel-Farley V, DeGregorio G, Holm IA, Khatwa U. Safety, pharmacokinetics, and preliminary assessment of efficacy of mecasermin (recombinant human IGF-1) for the treatment of Rett syndrome. Proc Natl Acad Sci U S A. 2014;111(12):4596-601. https://doi.org/10.1073/pnas.1311141111

116. Bozdagi O, Tavassoli T, Buxbaum JD. Insulin-like growth factor-1 rescues synaptic and motor deficits in a mouse model of autism and developmental delay. Mol Autism. 2013;4(1):1-4. https://doi. org/10.1186/2040-2392-4-9

117. Kolevzon A, Bush L, Wang AT, Halpern D, Frank Y, Grodberg D, Rapaport R, Tavassoli T, Chaplin W, Soorya L, Buxbaum JD. A pilot controlled trial of insulin-like growth factor-1 in children with PhelanMcDermid syndrome. Mol Autism. 2014;5(1):1-9. https://doi.org/10.1186/2040-2392-5-54

118. Zwanenburg RJ, Bocca G, Ruiter SA, Dillingh JH, Flapper BC, van den Heuvel ER, van RavenswaaijArts CM. Is there an effect of intranasal insulin on development and behaviour in Phelan-McDermid syndrome? A randomized, double-blind, placebo-controlled trial. Eur J Hum Genet. 2016;24(12): 1696-701. https://doi.org/10.1038/ejhg.2016.109

119. Vahdatpour C, Dyer AH, Tropea D. Insulin-like growth factor 1 and related compounds in the treatment of childhood-onset neurodevelopmental disorders. Front Neurosci. 2016;10:450. https://doi. org/10.3389/fnins.2016.00450

120. AMO-01 to Treat Adolescents and Adults With Phelan-McDermid Syndrome (PMS) and Co-morbid Epilepsy, ClinicalTrials.gov. 2021. 